\title{
Comparisons with wheat reveal root anatomical and histochemical constraints of rice under water-deficit stress
}

\author{
Wenjing Ouyang • Xinyou Yin • Jianchang Yang • \\ Paul C. Struik
}

Received: 22 November 2019 / Accepted: 23 May 2020 /Published online: 18June2020

(C) The Author(s) 2020

\begin{abstract}
Aims To face the challenge of decreasing freshwater availability for agriculture, it is important to explore avenues for developing rice genotypes that can be grown like dryland cereals. Roots play a key role in plant adaptation to dry environments.

Methods We examined anatomical and histochemical root traits that affect water acquisition in rice (Oryza sativa) and wheat (Triticum aestivum). These traits and root growth were measured at two developmental stages for three rice and two wheat cultivars that were grown in pots under three water regimes.

Results Wheat roots had larger xylem sizes than rice roots, which potentially led to a higher axial conductance, especially under water-deficit conditions. Suberization, lignification and thickening of the endodermis in rice roots increased with increasing water deficit, resulting in stronger radial barriers for water flow in rice
\end{abstract}

Responsible Editor: Hans Lambers

Electronic supplementary material The online version of this article (https://doi.org/10.1007/s11104-020-04581-6) contains supplementary material, which is available to authorized users.

W. Ouyang $\cdot$ X. Yin $(\bowtie) \cdot$ P. C. Struik

Centre for Crop Systems Analysis, Department of Plant Sciences, Wageningen University \& Research, PO Box 430, 6700

AK Wageningen, The Netherlands

e-mail: xinyou.yin@wur.nl

J. Yang $(\bowtie)$

College of Agriculture, Yangzhou University, 48 Wenhui East

Road, Yangzhou, Jiangsu 225009, China

e-mail: jcyang@yzu.edu.cn than in wheat, especially near the root apex. In addition, water deficit strongly impeded root growth and lateral root proliferation in rice, but only slightly in wheat, and cultivars within a species differed little in these responses. The stress sensitivity of rice attributes was slightly more prominent at vegetative than at flowering stages.

Conclusions Rice root characteristics, which are essential for growth under inundated conditions, are not conducive to growth under water deficit. Although rice roots show considerable plasticity under different watering regimes, improving root xylem size and reducing the radial barriers would be required if rice is to grow like dryland cereals.

Keywords Lignin $\cdot$ Rice $\cdot$ Root anatomy $\cdot$ Root morphology $\cdot$ Suberin $\cdot$ Water deficit $\cdot$ Wheat

\section{Introduction}

Climate change as well as the decreasing availability of freshwater resources for agriculture will increase the frequency and severity of water limitation for crop production (Madadgar et al. 2017). Rice (Oryza sativa L.), one of the major staple food crops, is very sensitive to even mild water-deficit (Pantuwan et al. 2002; Centritto et al. 2009), because of its (semi-)aquatic growth nature. Developing rice genotypes that maintain high productivity under water-deficit conditions is a major challenge for breeders and synthetic biologists. 
Rice is mostly grown under irrigated lowland conditions (i.e. in inundated paddy fields). However, natural diversity in water-deficit adaptation has allowed to develop rice cultivars for other types of production systems: aerobic (moderately dry soil without flooding) and dry upland (dry soils without irrigation) environments (Bouman et al. 2005; Peng et al. 2006). Irrigated lowland rice is high yielding, but its production requires large amounts of water and will be particularly constrained by the increasing freshwater scarcity (Peng et al. 2009). Aerobic and upland rice grow under drier conditions but at the cost of different levels of yield penalties (Bouman et al. 2005). Nevertheless, the adaptation of rice ecotypes to these ranges of edaphic conditions indicates that rice has the potential to grow like dryland cereals, such as wheat (Triticum aestivum L.). Roots are the first organs to sense the dehydration of soil and thus play an important role in plant adaptation to water-deficit conditions (Zingaretti et al. 2013). Comparative studies on differences of root traits in response to water deficit among rice ecotypes and between different species will possibly identify the mechanisms required for developing water-deficit tolerant, yet highyielding, rice varieties.

Rice and wheat root systems are mainly composed of nodal roots and extensively branched lateral roots (O’Brien 1979; O’Toole and Bland 1987). Nodal roots are important for anchoring plants in the soil (Krauss et al. 2003), acquiring water and nutrients, as well as transporting water and nutrients to the aerial parts (Steffens and Rasmussen 2016), while lateral roots contribute to the adhesion of the nodal root to the rhizosphere and regulate nutrients (Ma et al. 2001) and water (Zhan et al. 2015) acquisition from the soil. Genetic variation in root biomass and root morphology under the exposure to water deficit across diverse rice germplasms is well documented (Kato et al. 2006; Henry et al. 2011; Kadam et al. 2015). But the key root traits that are involved in plant adaptation to soil water deficit for different species are not fully understood.

The water uptake by roots involves first radial water transport from soil solution into root stele, and then axial water flow up into the shoot by through xylem vessels (Steudle and Peterson 1998). Apoplastic transport and symplastic transport are the two main radial pathways for water movement into the root (Steudle and Peterson 1998). Plasmodesmata facilitate symplastic paths and permit solutes to move between cells nonspecifically (Rutschow et al. 2011). Evidence suggests that the relative contribution of the apoplastic path to the overall hydraulic conductivity is higher than that of symplastic path in rice roots (Ranathunge et al. 2004). The hydraulic conductance of the apoplastic path is strongly affected by root anatomy (Steudle and Peterson 1998; Zimmermann et al. 2000). Like those of many other wetland species, rice nodal roots are characterized by an extensive intercellular space (i.e. aerenchyma) in the root cortex (McDonald et al. 2002). Such anatomical features are considered to provide a low internal resistance for gas movement within the roots, thereby enhancing rice root aeration (Drew et al. 2000; Colmer 2002; Suralta and Yamauchi 2008). However, this system may be developed at the cost of reducing the space for the vascular transport system.

Xylem vessels act as a duct which collects and transports water and minerals within the root and from the root to the shoot, thus directly affecting root axial hydraulic conductance (Steudle and Peterson 1998; Kim et al. 2014). The root axial conductance differences between species were related to differences in crosssectional area of matured xylem (Bramley et al. 2009). Genetic variation for xylem vessel diameter and number has also been shown in rice (Henry et al. 2012; Uga et al. 2013; Hazman and Brown 2018) and in wheat (Richards and Passioura 1981; Wasson et al. 2012). Xylem vessel diameter and number can be affected by water deficit (Henry et al. 2012). It should be noted that while mature late metaxylem vessels in the basal parts transfer water and nutrients to the shoot, protoxylem and early metaxylem vessels function in the apical part of the roots, in land plants (Baluska et al. 2013). However, the existing literature on root responses to water-deficit stresses mostly focuses on late metaxylem, whereas the contribution of protoxylem and early metaxylem vessels has largely been overlooked (Henry et al. 2011; Kadam et al. 2015).

The exodermis and endodermis are the outermost and innermost layers of the root cortex (Peterson and Cholewa 1998; Steudle and Peterson 1998). Previous studies have documented that structural features on root exodermis and endodermis, i.e. Casparian bands, suberin lamellae, lignin deposition and tertiary walls, are finely tuned in response to water deficit (Enstone et al. 2002; Henry et al. 2012; Geldner 2013; Tylová et al. 2017). A clear response is increased amounts of suberin and lignin, which form important components of endodermal cell walls (Henry et al. 2012; Lee et al. 2016; Ranathunge et al. 2017; Tylová et al. 2017; Kreszies 
et al. 2018). Suberization and lignification of root cell layers can restrict the movement of water into and within the root, mainly by reducing apoplastic transport (Ma and Peterson 2003; Lynch et al. 2014). However, differences in cell wall modifications between rice and wheat and the genetic variation within those species when exposed to different levels of water deficit are still not known.

Like our previous study (Kadam et al. 2015), studies focusing on root traits in response to water deficit were commonly carried out for one single growth stage and/ or a specific position of the root (Kashiwagi et al. 2006; Kano et al. 2011; Zhan et al. 2015; Prince et al. 2017). However, the sensitivity of rice plants to water-deficit might differ among developmental stages (Pantuwan et al. 2002; Centritto et al. 2009). Furthermore, root anatomical and histochemical properties are variable along spatially different root zones (Bramley et al. 2009; Kreszies et al. 2018). An extended understanding of the functional role of root plasticity for rice and wheat plant adapting to water deficit stress would require a detailed study.

Our main hypothesis was that the requirement extensive aerenchyma in rice as a (semi-)aquatic plant may have pushed for a reduced vascular transport system, thereby impeding the axial water flow transport in the root cylinder. We further hypothesized that suberization and lignification of root cell layers and other anatomical features that influence the ability of radial water transport differ between rice and dryland cereals in response to water deficit. Both axial and radial transport capability, if reduced, would contribute to the reduced tolerance of rice when grown under water-deficit conditions. Hence, in this study, we evaluated differences in root growth, aerenchyma, xylem vessel development, and histochemical features (i.e. lignin and suberin), between three rice genotypes and two wheat genotypes grown under water-deficit treatments, at both vegetative and flowering stages.

\section{Materials and methods}

Plant materials and treatments

Three rice ( $O$. sativa L., subsp. indica) cultivars and two wheat (T. aestivum L.) cultivars were selected based on their tolerance to water deficit. Among the three rice cultivars, the high-yielding lowland cv. IR 64-21
(IR64) is highly sensitive to water deficit (Venuprasad et al. 2008), the improved aerobic cv. NAIC RC9 (Apo) is moderately tolerant to water deficit (Venuprasad et al. 2007), and the improved upland cv. UPL Ri7 (UPL7) is tolerant to drought (Atlin et al. 2006). Wheat cultivar SeriM82 (S82) is moderately susceptible (Pfeiffer 1988) to tolerant (Villareal et al. 1995), while wheat cv. Weebill4 (We4) is highly tolerant (Praba et al. 2009), to water deficit. Seeds of rice and wheat were obtained from the International Rice Research Institute (IRRI) and from the International Maize and Wheat Improvement Center (CIMMYT), respectively.

Pot experiments were carried out in an open field, which was sheltered from rain by a mobile transparent polyethylene shelter, at Yangzhou University, China $\left(32^{\circ} 30^{\prime} \mathrm{N}, 119^{\circ} 25^{\prime} \mathrm{E}\right)$. Each pot $(30 \mathrm{~cm}$ in height and $25 \mathrm{~cm}$ in diameter) was filled with sandy loam soil from a local rice/wheat rotated field. Rice and wheat seeds were sown in their natural growth season (Table 1). Plants were managed as described by Ouyang et al. (2017). Three levels of soil moisture were imposed after seedling establishment, i.e. control (CT), mild drought (MD), and more severe drought (SD). Across species and treatments, three replications were maintained and placed in a completely randomized design. Because rice and wheat are naturally adapted to different moisture environments (Praba et al. 2009), different intensities of stress were imposed (Table 1). Soil water potential was monitored with a tensiometer (Institute of Soil Sciences, Chinese Academy of Sciences, Nanjing, China) installed in each pot at a depth of $15 \mathrm{~cm}$. We checked the tensiometer twice a day, and water was added to bring soil moisture back to the upper limit of the target stress when tensiometer readings reached the lower limit. Once stress was imposed, the target levels were maintained until all measurements were completed. Leaf water potential at midday (13:00-15:00 h) was measured at vegetative and flowering stages to monitor the stress level the plants were actually experiencing (Table S1). Three topmost fully expanded leaves of the main stems were chosen, and three to four discs (about $6 \mathrm{~mm}$ in diameter) from the middle part of the leaves were cut and sealed in the C-52 thermocouple psychrometer (Wescor PSYPRO, Inc., Logan, UT, USA). The readings were recorded by a water potential data logger in the psychrometric mode, and the average value from the same plant was considered to represent leaf water potential. 
Root sample preparation

Roots were sampled at vegetative and flowering stages. Because rice and wheat have different growth durations, rice samples for the vegetative stage were taken after 30 days, while wheat roots were taken after 20 days, of stress imposition. The root systems were washed from soil over a 1-mm sieve to minimize the loss of fine roots. Except for a few nodal roots used for cross-section samples (see below), all whole-plant root samples were stored in $70 \%$ alcohol at $4^{\circ} \mathrm{C}$ to analyze root morphology by scanning image analyses.

To make a meaningful comparison between rice and wheat, nodal roots were used for anatomical and histochemical measurements. Three to five healthy nodal roots (30-35 cm long for wheat, and $35-40 \mathrm{~cm}$ long for rice) per replicate per treatment were selected and excised at the root-shoot junction and stored in $25 \%$ (v/v) alcohol. Three segments (each $\sim 10 \mathrm{~mm}$ long) were obtained from three different positions along the excised nodal root: (1) 10-20 $\mathrm{mm}$ below the root-shoot junction; (2) three-quarters (3/4) of the root between the root-shoot junction and root apex; and (3) 30-40 $\mathrm{mm}$ above the root apex (Fig. 1a). Excised segments were embedded in 5\% low melting point agarose. Cross-sections were prepared by cutting those agarose blocks using a vibrating microtome (ZQP-86, Zhisun, Shanghai, China). Multiple transverse sections per segment were stored in 50\% (v/v) alcohol and washed several times with deionized water before being used for anatomical and histochemical analysis.

Samples for scanning were cut to fit the scanner tray and meticulously separated in water to avoid overlapping. An 8-bit grayscale image acquired at a resolution of 600 dots per inch with a flat image scanner (Epson Expression 1680 Scanner, Seiko Epson Corp., Tokyo, Japan) was analyzed for root length by using the WinRHIZO Root Analyzer System (Regent Instruments Inc., Quebec, Canada). Roots were classified by WinRHIZO according to their diameters. A diameter of $0.2 \mathrm{~mm}$ was designated as the threshold used to distinguish between thick and fine roots (Henry et al. 2011; Kato and Okami 2011). The fine to thick root length ratio then could be determined. Scanned root samples were oven-dried at $70^{\circ} \mathrm{C}$ to constant weight and root dry mass was determined.

Root anatomy

Cross-sectional images were analyzed by using ImageJ software (Bethesda, Maryland, USA) (Abràmoff et al.
2004). All anatomical properties such as cross sectional area, stele area, aerenchyma area, thickness of the inner tangential wall of endodermal cell, number and total cross sectional area of early metaxylem, and number and total cross sectional area of late metaxylem were determined in three to five sections per root segment. Note that water and minerals are absorbed into protoxylem vessels and then are transported upwards through early and late metaxylem (Kim et al. 2014). It was difficult to identify the protoxylem in our light microscopy images, and thus we investigated the properties of early metaxylem and late metaxylem. Stele area and aerenchyma area in proportion to cross sectional area, as well as averaged area of early metaxylem and late metaxylem were calculated from these data. A schematic sketch of measured anatomical properties is provided in Fig. $1 b$.

Histochemical detection of suberin and lignin

Suberin lamellae in root tissues were detected by staining cross-sections at $70^{\circ} \mathrm{C}$ for $10 \mathrm{~min}$ with a saturated solution of Sudan III (Merck, Darmstadt, Germany) dissolved in ethanol/water $(1: 1 ; \mathrm{v} / \mathrm{v})$, according to Gerlach (1984). Suberin lamellae were recognized by orange color under bright-field illumination (Axio Imager D2, Carl Zeiss, Germany). Lignin deposition in cross-sections was detected by staining for several minutes with phloroglucinol/ $\mathrm{HCl}$ at room temperature (Jensen 1962). Transverse sections were mounted in a mixture with $10 \%(\mathrm{v} / \mathrm{v}) \mathrm{H}_{2} \mathrm{SO}_{4}$ in $75 \%(\mathrm{v} / \mathrm{v})$ glycerol to prevent color fading. Lignified tissues were viewed as bright red/pink under bright-field illumination (Axio Imager D2, Carl Zeiss, Germany). Suberization and lignification of exodermis and endodermis were assessed for 3-5 roots per replicate. A scoring system similar to the one described by Enstone and Peterson (2005) was used to characterize suberin and lignin deposition in exodermis and endodermis: "0" represented no suberin or lignin staining (no detectable suberin lamella and lignin deposition); "1" to " 3 " represented slight to moderate suberin or lignin staining; and " 4 " to " 5 " represented strong to very strong suberin or lignin staining.

Theoretically calculated axial conductance

Theoretical axial conductance $\left(k_{\mathrm{h}} ; \mathrm{mg} \mathrm{m} \mathrm{MPa}{ }^{-1} \mathrm{~s}^{-}\right.$

$\left.{ }^{1}\right)$ was calculated with the modified Hagen- 
Table 1 Description of cultivation and water regimes (CT: control; MD: mild drought, and SD: more severe drought) for rice and wheat cultivars

\begin{tabular}{|c|c|c|c|c|c|c|c|c|c|}
\hline \multirow[t]{2}{*}{ Species } & \multirow[t]{2}{*}{ Sowing time } & \multirow{2}{*}{$\begin{array}{l}\text { Density } \\
\text { (seedlings } \\
\text { per pot) }\end{array}$} & \multirow[t]{2}{*}{ Soil pH } & \multirow{2}{*}{$\begin{array}{l}\text { Initial } \\
\text { soil moisture }\end{array}$} & \multirow{2}{*}{$\begin{array}{l}\text { Stress } \\
\text { imposed time } \\
\text { (leaves) }^{\mathrm{a}}\end{array}$} & \multirow{2}{*}{$\begin{array}{l}\text { Days to } \\
\text { flowering }\end{array}$} & \multicolumn{3}{|c|}{ Water regimes $^{\mathrm{c}}$} \\
\hline & & & & & & & $\mathrm{CT}$ & MD & SD \\
\hline O. sativa & June 2014 & 3 & $5.5-6.0$ & Saturated & 5 & $77-86$ & Inundated & 0 to $-5 \mathrm{kPa}$ & -20 to $-40 \mathrm{kPa}$ \\
\hline T. aestivum & $\begin{array}{c}\text { November } \\
2014\end{array}$ & 8 & $6.5-7.0$ & 0 to $-5 \mathrm{kPa}$ & 4 & $45-51$ & 0 to $-5 \mathrm{kPa}$ & -20 to $-40 \mathrm{kPa}$ & -50 to $-70 \mathrm{kPa}$ \\
\hline
\end{tabular}

\footnotetext{
${ }^{a}$ Leaf number on the main stem;

${ }^{\mathrm{b}}$ Days after stress imposition; because wheat cultivars were sown in winter and received stress in the next spring, days to flowering is presented as days after stress imposition rather than in days after seedling emergence for both species;

${ }^{c}$ expressed in soil water potential
}

Poisseuille's law described by Tyree and Ewers (1991):

$k_{\mathrm{h}}=\left(\frac{\pi \rho}{128 \eta}\right) \sum_{i=1}^{n}\left(d_{i}^{4}\right)$

where $d_{\mathrm{i}}$ is the diameter of the ith xylem vessel in meters, $\rho$ is the fluid density (assumed to be $1 \times 10^{9} \mathrm{mg} \mathrm{m}^{-3}$ ) and $\eta$ is the viscosity (assumed to be $1 \times 10^{-9} \mathrm{MPa} \cdot \mathrm{s}$ ).

\section{Statistical analyses}

To test the significance for the effects of cultivar, treatment, stage and their interactions on each parameter, data was statistically analyzed using a general linear model (GLM) with the $\mathrm{R}$ programming language (http://www.R-project.org/). Root position was included as an additional factor in the analysis of root anatomical and histochemical parameters. For these a

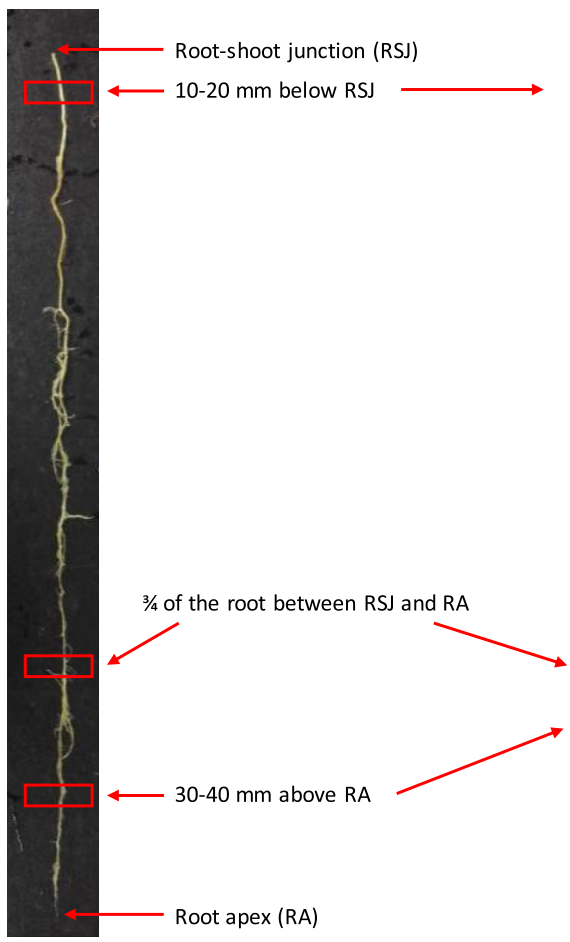

b Rice

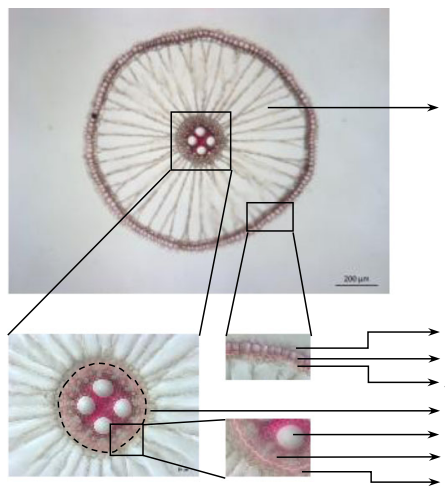

Wheat

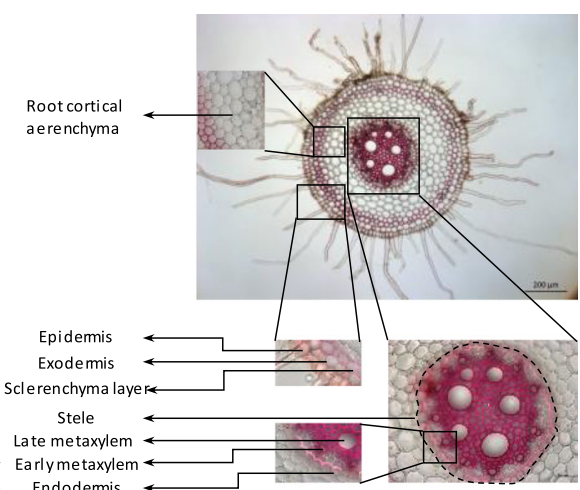

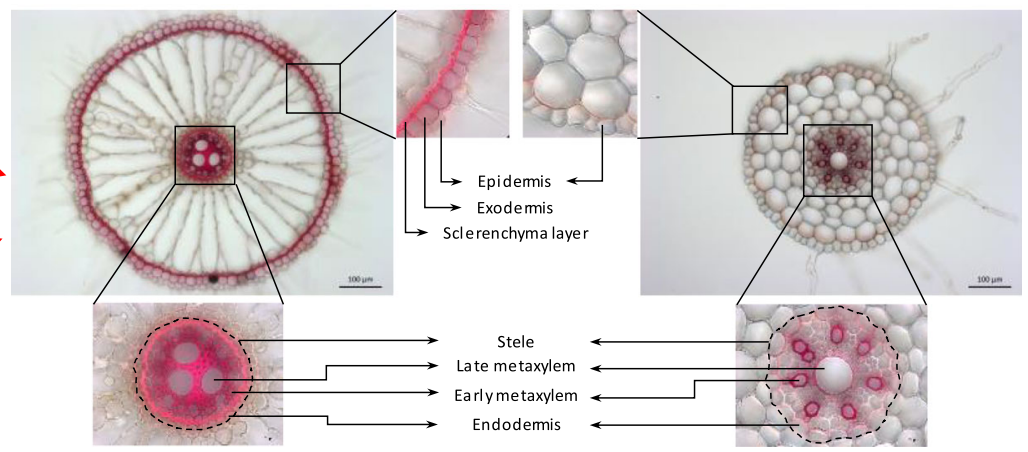

Fig. 1 Illustrations of (a) three sectioning positions along the root, and (b) root anatomical properties of rice and wheat with different crosssection structures. Sections stained with phloroglucinol- $\mathrm{HCl}$ and viewed under white light 
parameters, values of 3-5 nodal roots per replicate were averaged for the GLM analysis.

\section{Results}

Midday leaf water potential ( $\left.\Psi_{\text {leaf }}\right)$ varied largely between rice and wheat, with wheat having a significantly higher $\Psi_{\text {leaf }}$ than rice (Table S1). Across stages, both species had a lower $\Psi_{\text {leaf }}$ under water deficit treatments, although the MD treatment imposed to wheat was comparable to the SD treatment imposed to rice (Table S1). These data indicated the actual level of stress experienced by plants, with which we investigated root anatomical, histochemical and morphological traits.

\section{Root cross-section structures}

Root transversal structures were similar among cultivars within each species but differed between species (Fig. 2 and Fig. S1). In rice, the outer cell layers of all root crosssections contained exodermis and a tightly packed sclerenchyma layer cells between the exodermal and cortex cells (Figs. 1 and 2; Fig. S1, S2 and S3). In wheat, exodermis and sclerenchymatous cells (two or three layers) were only detected in the cross-sections near the root-shoot junction but not at the two lower positions (Figs. 1 and 2; Fig. S1, S2 and S3). The cortex of rice root contained a large proportion of intercellular spaces (aerenchyma), even under water-deficit treatments (Fig. 3 and Fig. S1). However, there was virtually no aerenchyma area in any root sections of wheat. At the vegetative stage, a negative effect of water-deficit stress on the formation of aerenchyma was detected in rice cultivars across all three positions (Fig. 3 and Fig. S4). At the flowering stage, the formation of aerenchyma at the position near the root-shoot junction in all rice cultivars was significantly reduced under both water-deficit treatments $(\mathrm{P}<0.001$ for MD and SD; Fig. 3a). However, the formation of aerenchyma at the two lower sectioning positions was affected by SD $(\mathrm{P}<0.001)$ but not by MD (P > 0.05) (Fig. 3b-c).

Rice had significantly larger $(\mathrm{P}<0.001)$ root cross sectional area than wheat, regardless of cultivar, position and stage (Fig. 4a-c, Fig. S1). Compared with the vegetative stage, the cross sectional area at the flowering stage was lower in all rice cultivars at all three positions but was relatively consistent (S82) or increased (We4) in wheat (Fig. $4 \mathrm{a}-\mathrm{c}$ ). The cross sectional area in rice was
Fig. 2 Light microscopy images of nodal roots for the representative genotypes, cv. IR 64 for rice and cv. We4 for wheat, grown under control (CT), mild drought (MD), and more severe drought (SD) conditions. Root segments were sampled at 10 to $20 \mathrm{~mm}$ below root-shoot junction, $3 / 4$ of the root between root-shoot junction and root apex, and 30 to $40 \mathrm{~mm}$ above root apex, at (a) vegetative and (b) flowering stages. Cross-section, suberin and lignin deposition pattern in the inner part of the root were presented. ae, aerenchyma; co, cortical cells; en, endodermis; mxy, late metaxylem; exy, early metaxylem. Each scale bar represents $100 \mu \mathrm{m}$ for wheat cross-section images at 3/4 of the root between root-shoot junction and root apex and 30 to $40 \mathrm{~mm}$ above root apex, and $200 \mu \mathrm{m}$ for other cross-section images. Each scale bar represents $20 \mu \mathrm{m}$ for suberin and lignin deposition images. Images for all genotypes are shown in Supplementary Fig. S1

reduced by water-deficit treatments $(\mathrm{P}<0.001)$, and the reduction was less at 10-20 $\mathrm{mm}$ below root-shoot junction (up to $18 \%$ decrease under the SD condition) than at the other two positions (up to 55\% decrease under the SD condition) (Fig. 4a-c). Furthermore, the treatment effect on cross sectional area in rice was stronger at the vegetative than at the flowering stage (Fig. 4a-c). Conversely, water-deficit treatments significantly increased the cross sectional area at $10-20 \mathrm{~mm}$ below the rootshoot junction in both wheat cultivars at the vegetative stage, as well as in S82 at the flowering stage (Fig. 4a). Water-deficit treatments did not significantly affect cross sectional area at the other positions in wheat at both stages (Fig. 4b and c).

Wheat had a much higher stele area than rice, especially at $10-20 \mathrm{~mm}$ below root-shoot junction (Fig. 4d-f). In each species, cultivars with larger root cross sectional area under control and water-deficit conditions also showed larger stele areas. This trend was confirmed by the significant positive correlation between root cross sectional area and stele area under each treatment at all positions (data not shown). Furthermore, an increasing trend in stele area under water-deficit conditions across positions and stages was observed in both species, although the trend was more clear in wheat roots (Fig. 4d-f).

Across positions, stages and treatments, the stele area to root cross sectional area ratio was significantly higher in wheat than in rice (Fig. 4g-i). In both species, waterdeficit treatments had a significant, positive effect on the ratio across all three positions, with a higher increase of the ratio under water-deficit treatments in rice (up to $119 \%$ ) than in wheat (up to $31 \%$ ) (Fig. 4g-i). Additionally, the increase in the ratio at the two lower positions was stronger than that near the root-shoot junction in all cultivars of both species at both stages (Fig. 4g-i). 


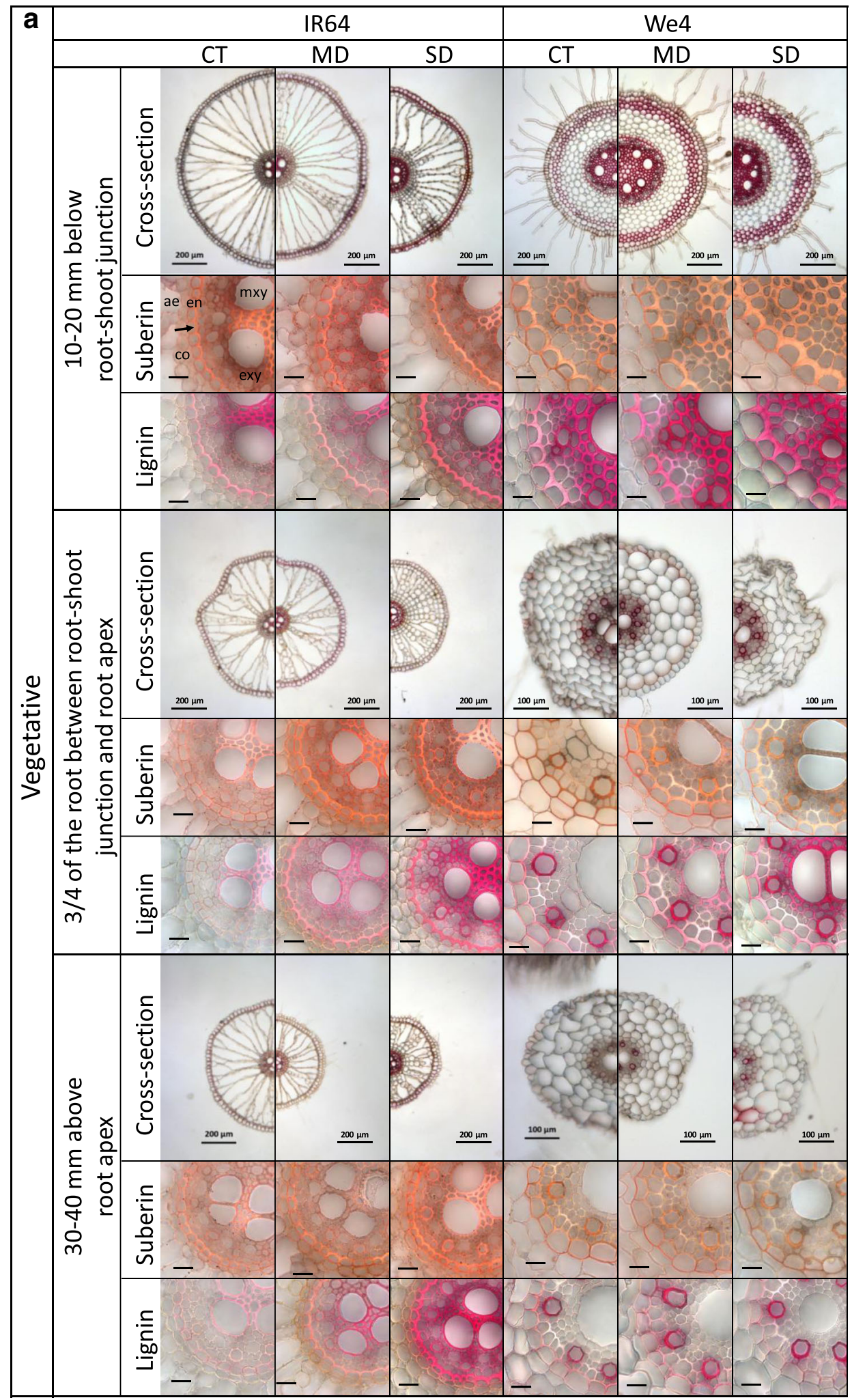




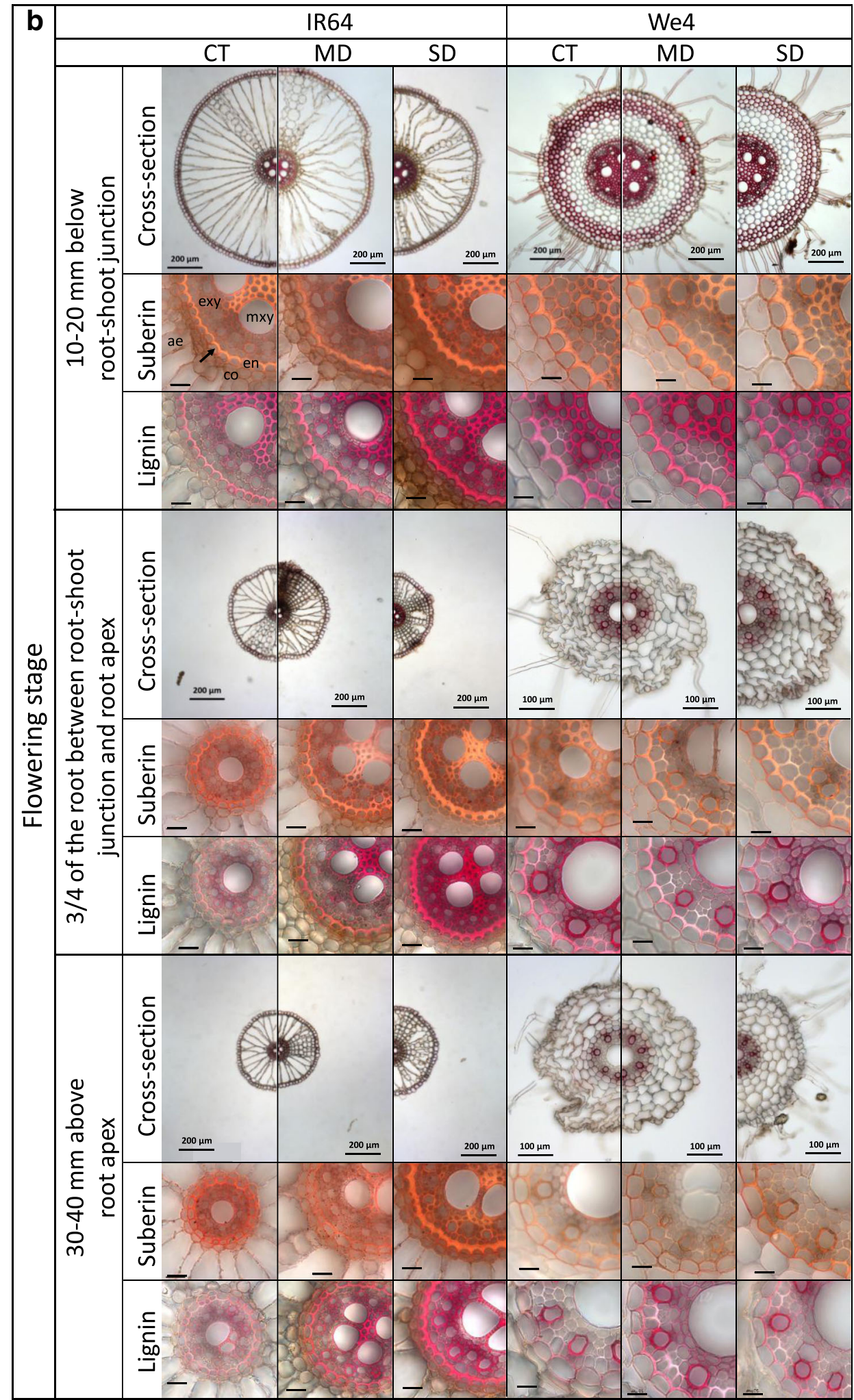

Fig. 2 (continued) 
Fig. 3 Response of aerenchyma percentage of root cortex area along nodal roots of rice and wheat to water treatments: control (CT), mild drought (MD), and more severe drought (SD). Root cross-sections were taken at (a) 10 to $20 \mathrm{~mm}$ below root-shoot junction, (b) 3/4 of the root between root-shoot junction and root apex, (c) 30 to $40 \mathrm{~mm}$ above root apex, at vegetative and flowering stages. Bars represent standard errors of the mean for three replicates. Due to the large differences of the aerenchyma area and in proportion to the root cortex area between rice and wheat cultivars, data for wheat are shown in insets
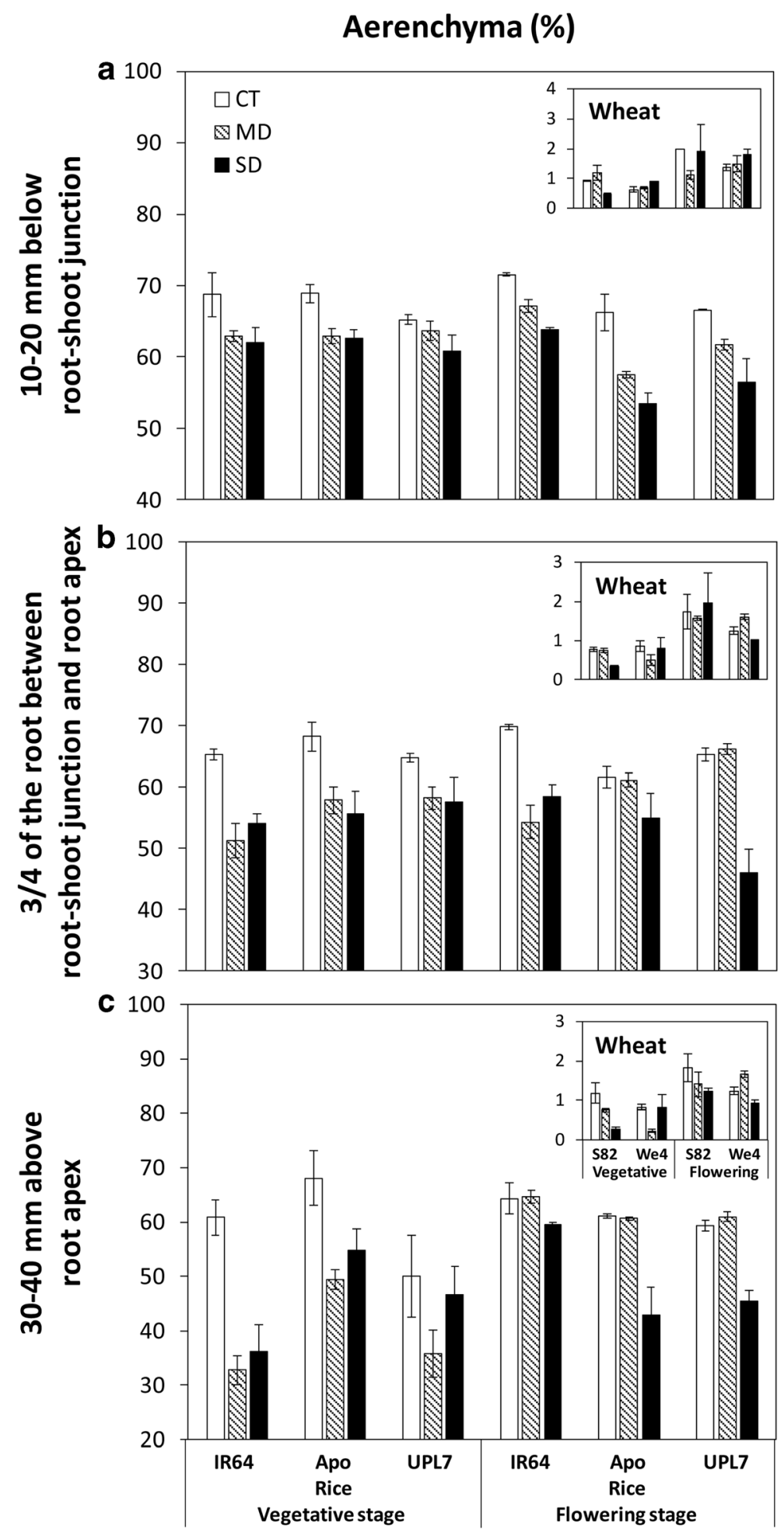

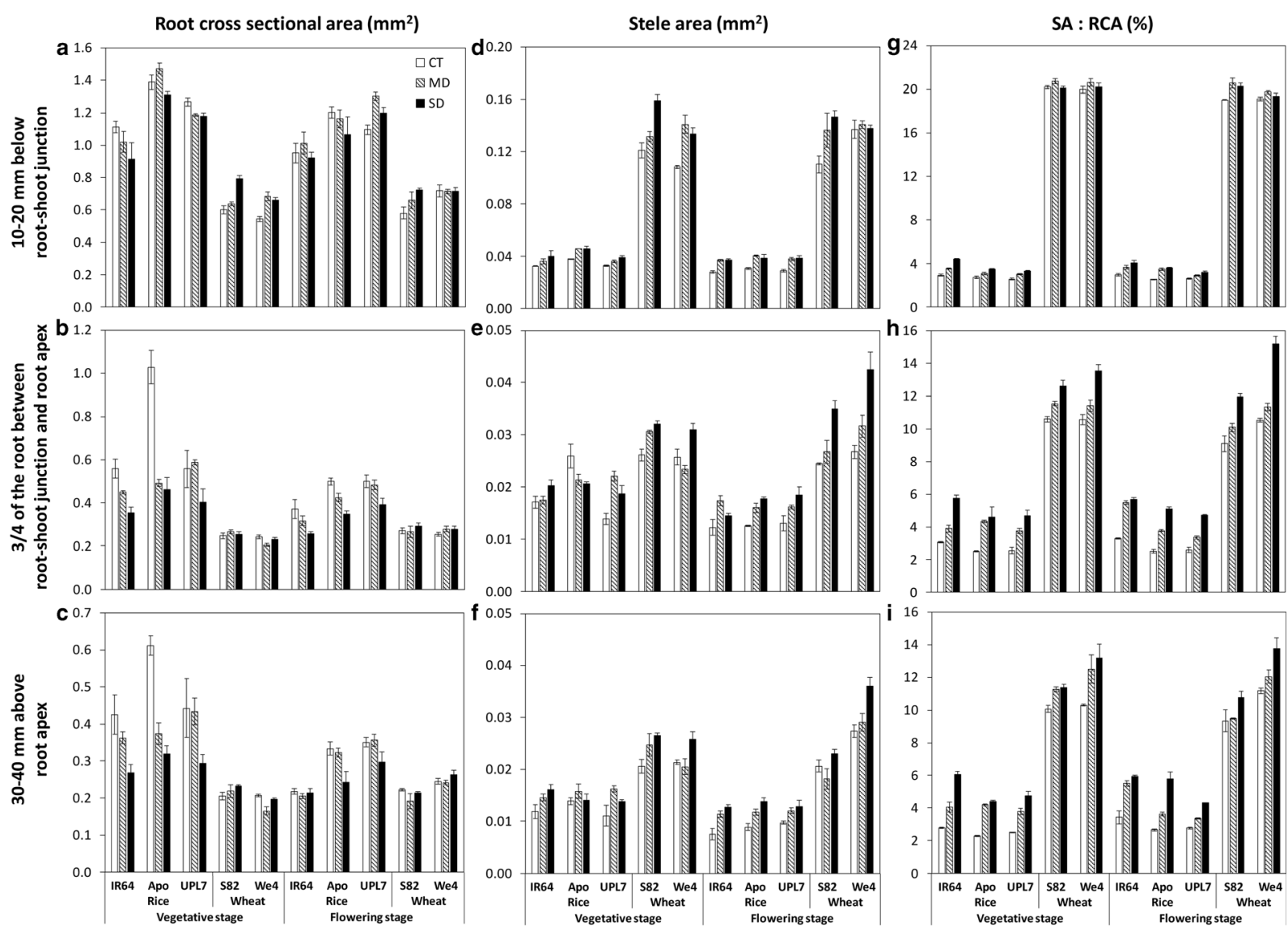

Fig. 4 Response of (a-c) root cross sectional area, (d-f) stele area and (g-i) stele area to root cross sectional area ratio (SA:RCA) along nodal roots of rice and wheat to water treatments: control (CT), mild drought (MD), and more severe drought (SD). Root cross-sections were taken at (a, d, g) 10 to $20 \mathrm{~mm}$ below root- shoot junction, (b, e, h) 3/4 of the root between root-shoot junction and root apex, (c, f, i) 30 to $40 \mathrm{~mm}$ above root apex, at vegetative and flowering stages. Bars represent standard errors of the mean for three replicates

\section{Modifications of the endodermis}

Endodermis is the connection between root cortical cells and stele (Fig. 1b). Three consecutive developmental stages of endodermis can be distinguished: (i) primary stage during which endodermal cell walls are impregnated with Casparian bands; (ii) secondary stage characterized by the uniform deposition of a thin suberin lamella to the inner surface of radial and tangential walls of the endodermal cells; and (iii) the tertiary stage with heavy U-shaped cell wall deposition on the inner tangential cell walls of the endodermal cells (Schreiber et al. 1999). Under the CT condition, the endodermis at $10-20 \mathrm{~mm}$ below the root-shoot junction in both species was in the tertiary stage whereas the endodermis at the two lower positions was in the secondary stage (Fig. 2, Fig. S2 and S3). Wheat showed a significantly thicker inner tangential wall of the endodermis than rice $(\mathrm{P}<0.001)$ under the $\mathrm{CT}$ condition, especially at the root-shoot junction (Fig. 5, Fig. S2 and S3). Under water-deficit conditions, a transformation of the endodermis from secondary to tertiary stage at the two lower positions was observed in rice but not in wheat (Fig. 2 and Fig. S2). Water deficit significantly thickened the inner tangential wall of the endodermis in all root positions in all rice cultivars, but the thickening was less marked in UPL7 (Fig. 5). Higher degree of thickening at the two lower positions (up to $183 \%$ increase under the SD condition) than at the root-shoot junction (up to $80 \%$ increase under the SD condition) was observed in rice. Furthermore, a greater treatment-induced thickening of the inner tangential wall in rice was observed at flowering (up to $183 \%$ increase under the SD condition) than that at the vegetative stage (up to $139 \%$ increase 
Fig. 5 Response of the thickness of the inner tangential wall of the endodermis along nodal roots of rice and wheat to water treatments: control (CT), mild drought (MD), and more severe drought (SD). Root cross-sections were taken at (a) 10 to $20 \mathrm{~mm}$ below root-shoot junction, (b) 3/4 of the root between root-shoot junction and root apex, (c) 30 to $40 \mathrm{~mm}$ above root apex, at vegetative and flowering stages. Bars represent standard errors of the mean for three replicates
Thickness of inner tangential wall
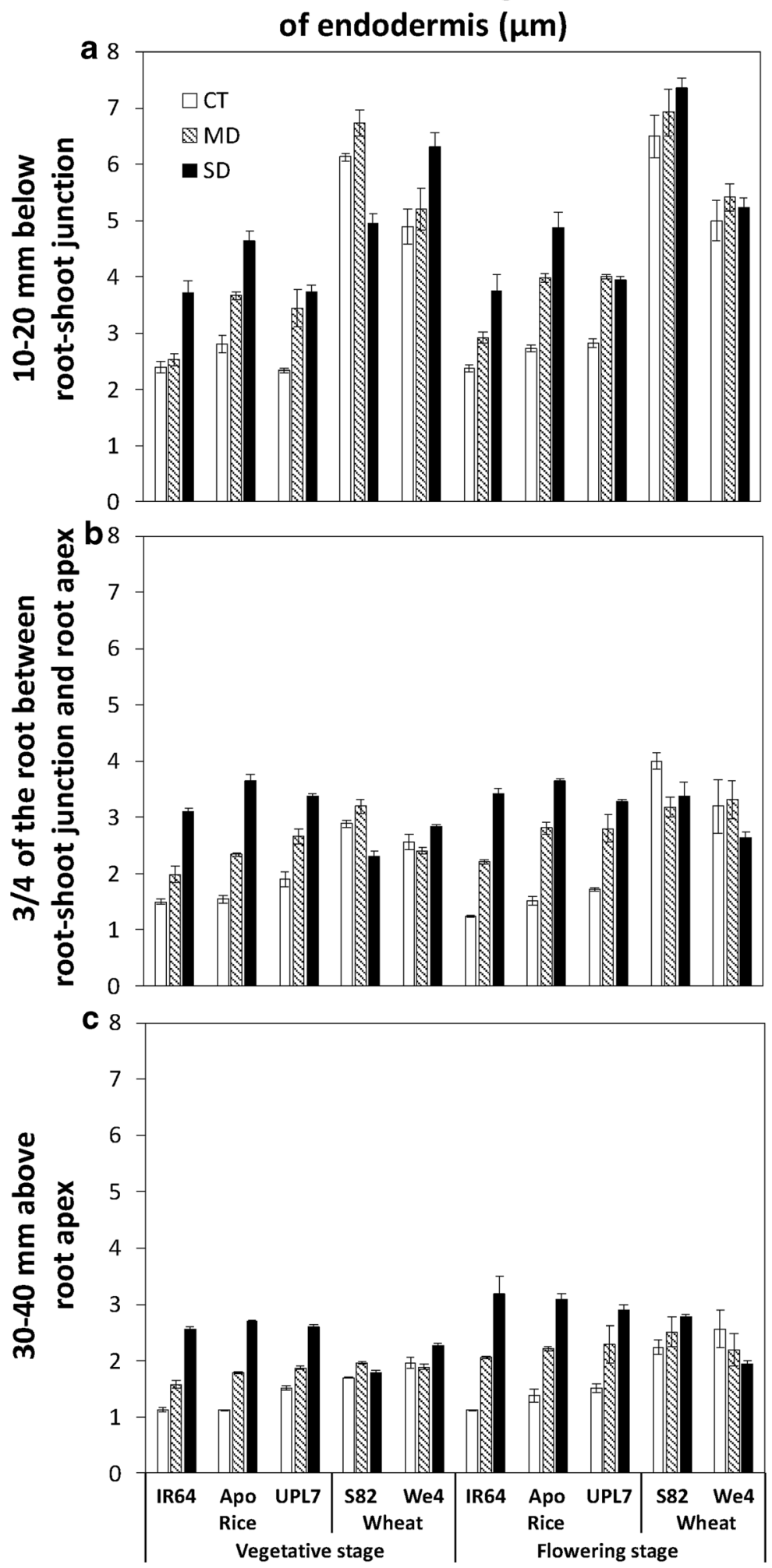
under the SD condition) (Fig. 5). On the other hand, water-deficit treatments did not induce remarkable changes on the thickness of the inner tangential wall at any position of wheat root ( $\mathrm{P}>0.05$; Fig. 5, Fig. S2 and S3). It is noteworthy that, wheat maintained a thinner inner tangential wall than rice at the two lower root positions under both water-deficit treatments (Fig. 5, Fig. S2 and S3).

Early metaxylem and late metaxylem

The early and late metaxylem vessels were well lignified in rice at all positions and both stages, even under the CT condition (Fig. S3). At 30-40 mm above the apex of wheat roots, the early metaxylem was well lignified but the central late metaxylem was not, indicating the immaturity of the late metaxylem vessels (Fig. S3).

The early metaxylem number was not strongly variable among species (Fig. S5a-c). Across positions and stages, water-deficit treatments did not induce a clear effect on the early metaxylem number in both species (Fig. S5a-c). The total early metaxylem area was two to four times larger in wheat than in rice, regardless of sectioning positions, stages and treatments (Fig. 6a-c). Water deficit increased the total early metaxylem area in both species (Fig. 6a-c). Averaged area per early metaxylem, an indicator of the size of individual early metaxylem, was calculated as the total area by the number of early metaxylem vessels. Under all growing conditions, wheat had a significantly higher averaged area per early metaxylem than rice, and the difference was larger at the two lower positions (Fig. S5d-f). In both species, water deficit increased the averaged area per early metaxylem across positions and stages (Fig. S5d-f). As expected, the calculated axial conductance of early metaxylem (Fig. S6a-c) followed a similar pattern as the total early metaxylem area (Fig. 6a-c). Water deficit treatments increased the axial conductance of early metaxylem in both species, with a higher increase at the two lower positions (up to $177 \%$ under the SD condition) than that at $10-20 \mathrm{~mm}$ below the root-shoot junction in wheat (up to $87 \%$ under the SD condition) but not in rice (Fig. S6ac).

The late metaxylem number was significantly higher at the 10-20 mm below root-shoot junction in wheat, but much lower at the two lower positions than in rice (Fig. S5g-i). Water-deficit treatments did not induce a clear pattern of late metaxylem number across positions in both species, except for an increase in the late metaxylem number at the 10-20 mm below root-shoot junction in wheat (Fig. S5g-i). In general, the total late metaxylem area was higher in wheat than in rice at all three positions, and the difference was much larger at the 10-20 mm below root-shoot junction (Fig. 6d-f). Across stages, water-deficit treatments induced a clear increase in the total late metaxylem area at the 10-20 $\mathrm{mm}$ below root-shoot junction in rice and at all three positions in wheat (Fig. 6d-f). The averaged area per late metaxylem, as a measure of the individual late metaxylem size, was obtained from total late metaxylem area and number. Compared to rice, wheat had a significantly higher averaged area per late metaxylem $(\mathrm{P}<0.001)$ at all positions (Fig. S5j-1). No clear pattern of the averaged area per late metaxylem was observed with waterdeficit exposure in both species (Fig. S5j-1). Across positions and stages, wheat had a significantly higher calculated axial conductance of late metaxylem than rice (Fig. S6d-f). Water-deficit treatments increased the axial conductance of late metaxylem at the two upper positions in most cultivars (Fig. S6d and S6e). However, a clear pattern was not observed at 30 to $40 \mathrm{~mm}$ above root apex (Fig. S6f).

Suberin and lignin deposition

In the outer cell layers, suberin and lignin deposition was mainly observed in the sclerenchyma layer in all rice cross sections, and in the sclerenchyma layers and exodermal cells in wheat at $10-20 \mathrm{~mm}$ below the rootshoot junction (Fig. S2 and S3). In both species, the suberin and lignin deposition in endodermal cells varied significantly with cultivar and position along the root (Table S2, Fig. S2 and S3). Under the CT condition, the degree of suberization and lignification in the endodermis at $10-20 \mathrm{~mm}$ below the root-shoot junction was higher than that at the two lower positions in both species (Figs. 2 and 7, Fig. S2 and S3), with wheat showing a greater difference. A significant species $\times$ treatment effect $(\mathrm{P}<0.001)$ was observed for the degree of suberization. In rice, water-deficit stress significantly increased the suberization of endodermis $(\mathrm{P}<0.001)$, with significant interaction between treatment and position $(\mathrm{P}<0.001)$, between cultivar and treatment $(\mathrm{P}<$ $0.001)$, but no significant interaction between treatment and stage $(P>0.05)$ (Fig. S2, Table S2). Particularly, the increase in the suberization under water-deficit treatments was much larger at the two lower positions than at the root-shoot junction (Figs. 2 and 7a-c, Fig. S2). 

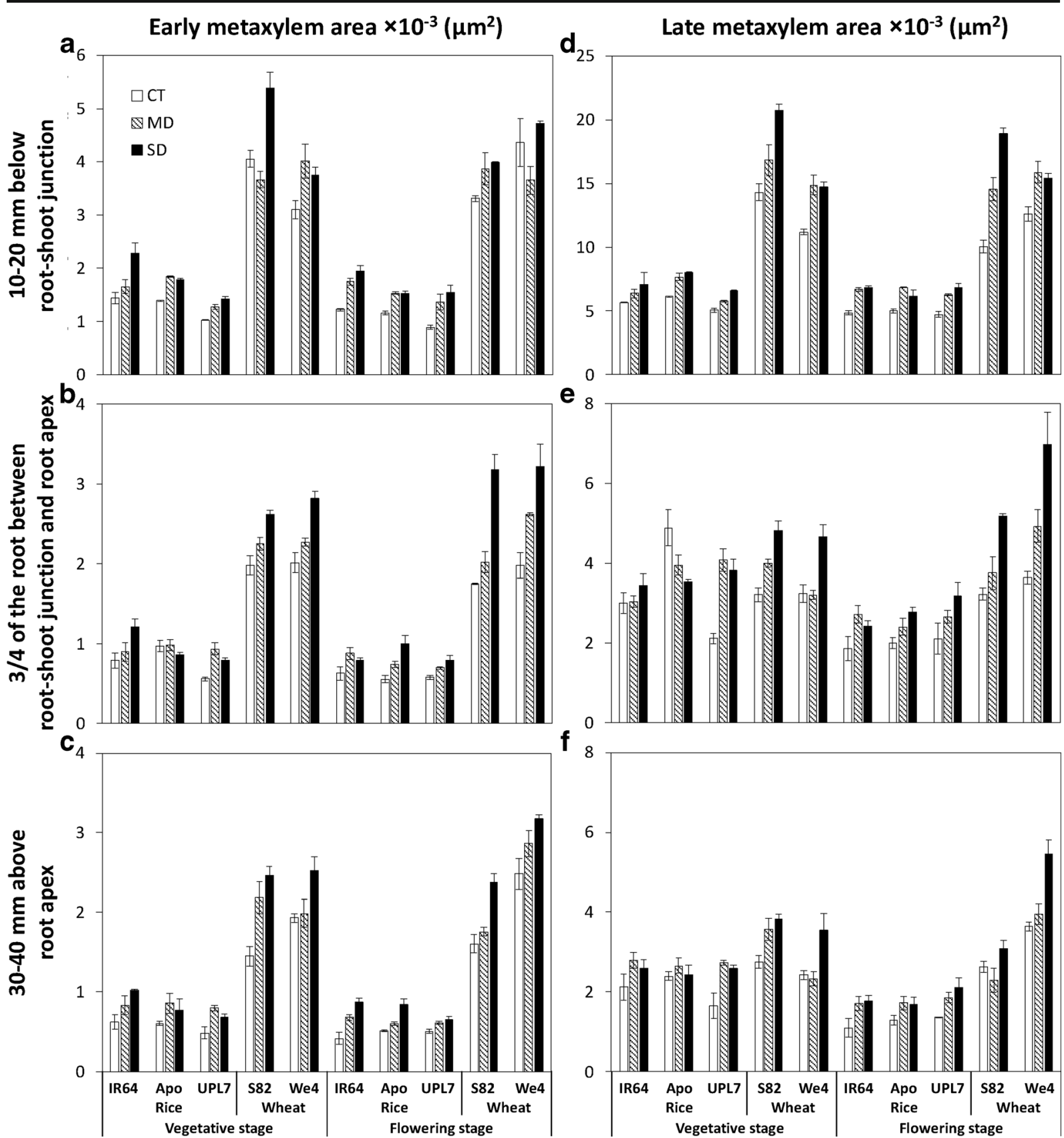

f 8

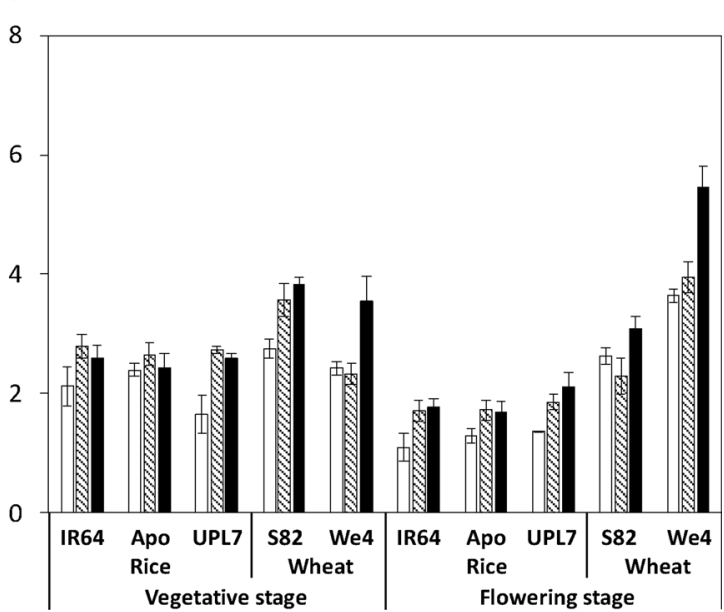

Fig. 6 Response of (a-c) early metaxylem area, and (d-f) late metaxylem area along nodal roots of rice and wheat to water treatments: control (CT), mild drought (MD), and more severe drought (SD). Root cross-sections were taken at (a, d) 10 to $20 \mathrm{~mm}$

below root-shoot junction, (b, e) 3/4 of the root between root-shoot junction and root apex, and (c, f) 30 to $40 \mathrm{~mm}$ above root apex, at vegetative and flowering stages. Bars represent standard errors of the mean for three replicates

Furthermore, water-deficit induced changes on the degree of lignification of endodermal cells in rice was similar as that on the degree of suberization of endodermal cells (Figs. 2 and 7d-f, Fig. S3). Also, a significantly lower increase of suberization and lignification was observed in UPL7, compared to other rice cultivars (Fig. 7, Fig. S2 and S3). However, the water-deficit treatment effect on suberization and lignification of endodermis was not prominent in wheat at both stages (Figs. 2 and 7, Fig. S2 and S3). 


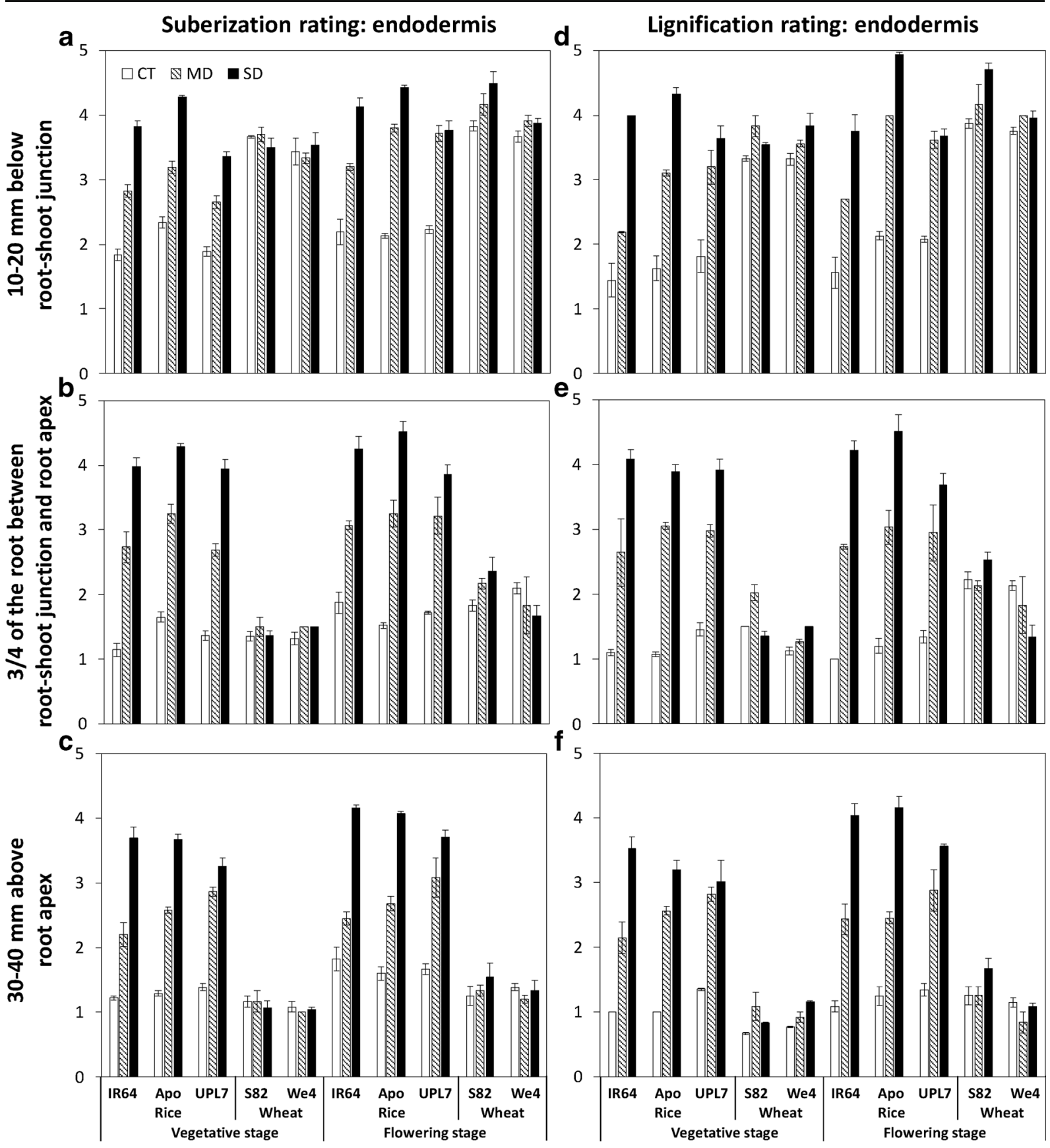

Fig. 7 Response of (a-c) suberin and (d-f) lignin deposition rating value of root endodermis along nodal roots of rice and wheat to water treatments: control (CT), mild drought (MD), and more severe drought (SD). Root cross-sections were taken at (a, d) 10

\section{Root morphology}

Significant variation in root biomass and in total root length per plant was observed among species $(\mathrm{P}<$ 0.001), and rice had much higher root biomass and root to $20 \mathrm{~mm}$ below root-shoot junction, (b, e) $3 / 4$ of the root between root-shoot junction and root apex, and (c, f) 30 to $40 \mathrm{~mm}$ above root apex, at vegetative and flowering stages. Bars represent standard errors of the mean for three replicates

length than wheat at both stages (Fig. 8a and b). A significant species $\times$ treatment effect $(\mathrm{P}<0.001)$ was observed for root biomass and root length (Table S3). Water deficit significantly decreased root biomass and length in all rice cultivars, with a reduction of up to $60 \% /$ 
$48 \%$ (vegetative/flowering) of root biomass and up to $78 \% / 68 \%$ (vegetative/flowering) of root length by the SD condition (Fig. 8a and b). Lower biomass and shorter length were observed under water-deficit conditions in lowland rice cultivar IR64, compared with the other two cultivars. The highest reduction of root biomass in wheat was $34 \%$, recorded in We4 under the SD condition at the flowering stage. Furthermore, water deficit only had a small effect $(0.05<\mathrm{P}<0.1)$ on root length for wheat cultivars, except for $\mathrm{We} 4$ under the SD condition (32\% reduction) at the flowering stage.

Fine-to-thick root length ratio is a proxy for the lateral to nodal root length ratio. The fine-to-thick root length ratio varied significantly among species, with rice having a significantly higher ratio than wheat (Fig. $8 \mathrm{c}$ ). A significant species $\times$ treatment $\times$ stage effect $(\mathrm{P}<$ 0.01 ) on this ratio was observed. Across all rice cultivars, water-deficit stress significantly decreased this ratio $(\mathrm{P}<0.001)$, with a larger reduction at the vegetative stage (up to 54\%) than that at the flowering stage (up to $36 \%$ ) (Fig. 8c). However, the ratio in wheat was not significantly affected by water-deficit treatments (P > 0.05; Table S3).

\section{Discussion}

The attributes of rice root may have pushed for a reduced axial transport capacity

Root aerenchyma is commonly formed in wetland species (Drew et al. 2000; Vysotskaya et al. 2004; Abiko et al. 2012; Argus et al. 2015), to enable an efficient supply of oxygen to roots when plants grow under hypoxic conditions (Suralta and Yamauchi 2008). This was confirmed by our data for the large cortex area with a high proportion of aerenchyma in rice root (Figs. 2 and 3; Fig. S1 and S4). A reduced but yet high proportion of aerenchyma has been observed in water-limited rice roots (Fig. 3), confirming the result of Suralta and Yamauchi (2008).

The root cross sectional area depends on the area of its cortex as well as the size of the stele. However, compared to wheat roots, the larger root cross sectional area in rice was only linked to the larger cortex area which was composed of a high proportion of aerenchyma, since rice roots had a much lower stele area at all positions than wheat roots (Figs. 3 and 4 and Fig. S1).
Such differences between rice and wheat support our first hypothesis that rice as a (semi-)aquatic plant requiring extensive aerenchyma may have pushed for a reduced vascular transport system.

Individual and total areas of early as well as late metaxylem were much smaller in rice than in wheat, regardless of position and stage (Fig. 6 and Fig. S5). Smaller xylem vessels have lower potential for water flow (Bramley et al. 2009), since the hydraulic conductance varies with the fourth power of the vessel diameter (Calkin et al. 1986; Eq. 1). Hence, rice cultivars would have a much lower axial water transport than wheat cultivars because of the lower xylem areas. This was confirmed with the calculated axial conductance, which indicated the maximum overall axial hydraulic conductance (Fig. S6). Furthermore, under water-deficit conditions, the early and late xylem area in wheat roots showed a more prominent response to water-deficit than rice roots (Fig. 6), which would result in a higher axial water transport in wheat than in rice under water-limited conditions (Fig. S6).

We also observed more specific differences in xylem development between rice and wheat. Lignification of xylem vessels indicates the maturity of xylem (Brundrett et al. 1988). A previous study using fluorescence images revealed that the early metaxylem was lignified far closer to the root tip than the central late metaxylem vessel in wheat roots (Bramley et al. 2009). Our histochemical staining of lignin in the xylem vessel confirmed this (Fig. S3). The immaturity of the late metaxylem at the lowest sectioning position in wheat (Fig. S3) indicated that the central vessel in wheat may become functional at greater distances from the root tip (Bramley et al. 2009). Furthermore, our result revealed that the axial conductance of early metaxylem near root tips in wheat responded more prominently than that of late metaxylem when exposed to water-deficit treatments (Fig. S6). However, such phenomena were not observed in rice. We therefore surmise that the water axial transport close to the root tip in wheat roots mainly depends on the early metaxylem, regardless whether they grow in well-watered or drought-stressed conditions. On the other hand, matured early and late metaxylem were observed in all rice cross-sections (Fig. S3). If all mature metaxylem vessels function for water transport, this might be beneficial for plants with a high demand of transpiration under inundation but might cause a risk of xylem embolism when water uptake is limited in stressed plants (Cochard 2002). 
Fig. 8 Response of root morphological parameters of rice and wheat cultivars to water treatments: control (CT), mild drought (MD), and more severe drought (SD). (a) Root biomass, (b) root length, and (c) fine-tothick root length ratio, at vegetative stage and flowering stage. Bars represent standard errors of the mean for three replicates

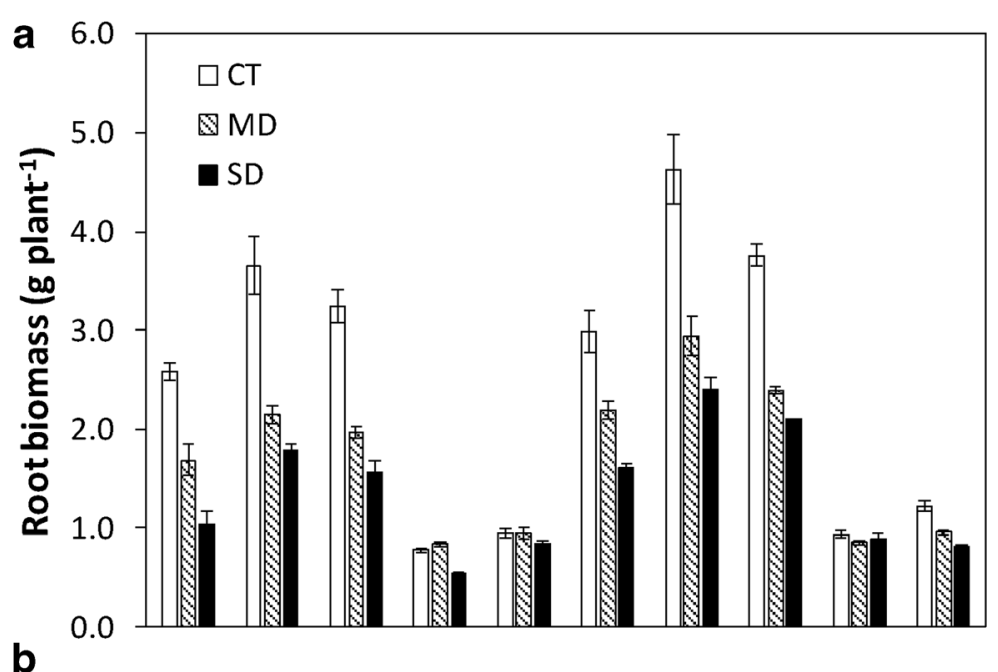

b
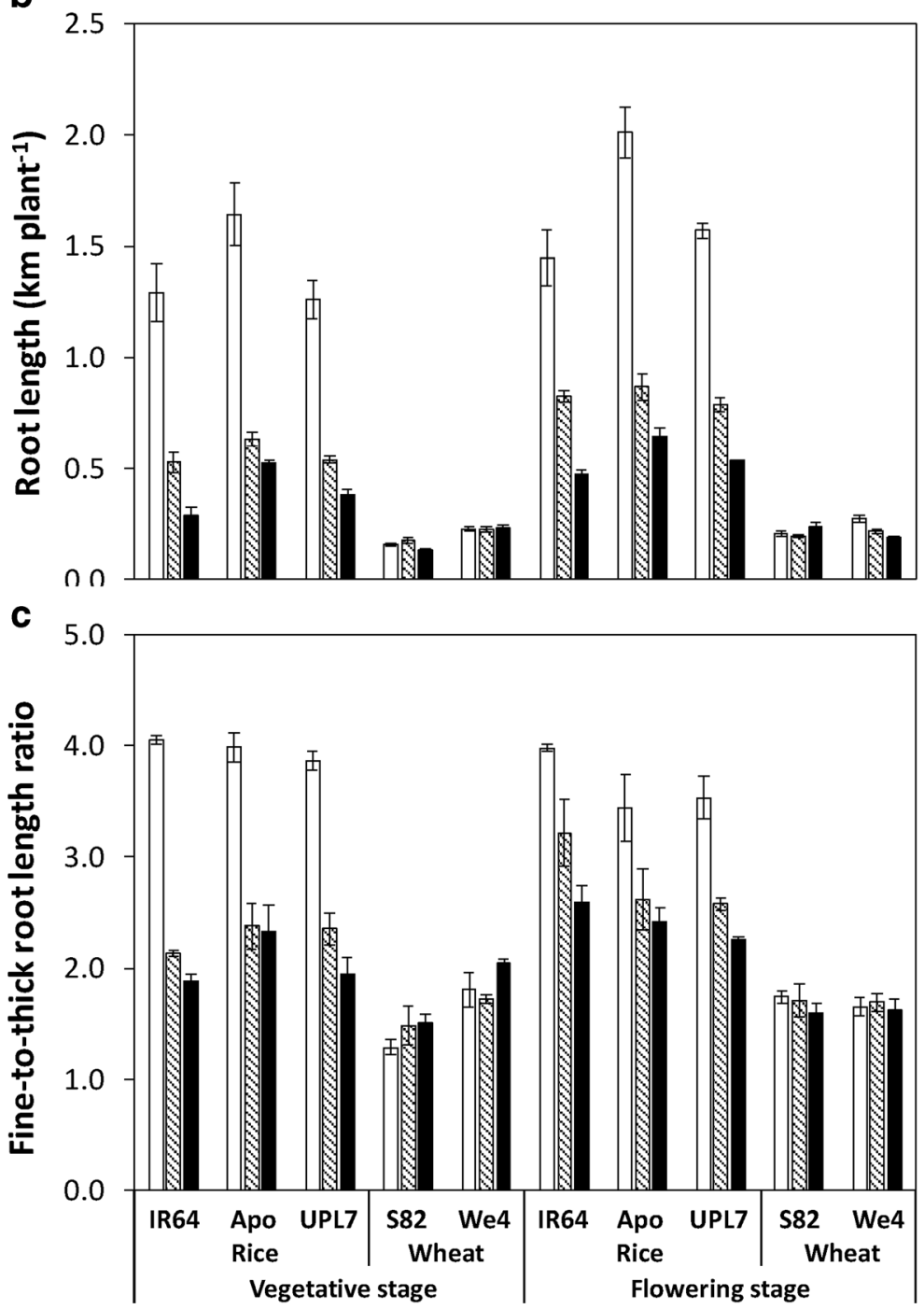
Anatomical and histochemical changes suggest a lower radial transport capacity in rice than wheat under water-deficit conditions

Water needs to pass through several layers of cortical cells to reach the endodermis. Rice had greater root cross sectional area, smaller stele area, and the resultant smaller stele to root cross sectional area ratio than wheat (Fig. 4), similar to commonly observed differences between wetland species and dryland species (McDonald et al. 2002). This suggests a longer radial distance for water transport in rice roots than in wheat. An increase in the stele to cross sectional area ratio along the root axis in response to water deficit was observed in both species (Fig. 4g-i), which would shorten the radial path across the cortical cells, thus helping improve the radial conductance for water flow (Chimungu et al. 2014; Lynch et al. 2014). The increase of the stele to cross sectional area ratio under water-deficit treatments in rice (Fig. 4g-i) was mainly due to the reduction of the cross sectional area (Fig. 4a-c). On the other hand, in wheat, the stress-induced increase in stele to cross sectional area ratio (especially at the two lower positions) was only due to the increase in stele area (Fig. 4d-f), since the root cross sectional area in wheat was not influenced by the treatments (Fig. 4a-c). Although both strategies helped reduce the radial path for water flow, it was at the expense of reducing the absorptive surface root area in rice, which would impede water acquisition under water-deficit conditions (Comas et al. 2013).

The suberized exodermis and lignified sclerenchyma layer in the outer part of the rice root was suggested to act as apoplastic barrier to prevent oxygen loss from aerenchyma to soil under oxygen-deficient conditions (Colmer 2002; Kotula et al. 2009), but may impede water and nutrient uptake of wetland species (Končalová 1990). However, we did not observe any regular suberin or lignin staining in the outer part of the roots (i,e. exodermal cells and sclerenchyma layers) in both species (data not shown). This was not caused by the staining procedure, as the endodermal cells were well stained in the same sections (Fig. S2 and S3). This led us to speculate that the outer part of rice root might act as an additional apoplastic barrier and not be responsive to water-deficit. On the other hand, the presence of exodermis and highly suberized/lignified sclerenchymatous cells in wheat roots was only observed near the root-shoot junction (Fig. S2 and S3). The absence of exodermis at the two lower positions in wheat root was similar to what has been reported for some dryland cereals such as maize (Abiko et al. 2012) and barley (Ranathunge et al. 2017).

The endodermis is regarded as the main apoplastic transport barrier for passive uptake of water from dry soil (Schreiber et al. 1999; Geldner 2013; Miyamoto et al. 2001; Enstone et al. 2002; Ranathunge et al. 2017). Water-deficit stress generally leads to larger parts of the root developing secondary and tertiary developmental stage of the endodermis (North and Nobel 1995; Schreiber et al. 1999). Thickened tertiary endodermal cell walls contained significantly higher amounts of lignin and suberin, compared to endodermal cell walls in their primary state of development (Zeier and Schreiber 1998). Our anatomical and histochemical observations in rice roots confirmed this by showing an increased suberization, lignification and thickening of the inner wall of the endodermis under water-deficit conditions (Figs. 5 and 7, Fig. S2 and S3). Yet, we did not observe such modification in wheat root sections.

Because of the hydrophobic nature of suberin, suberized cell walls in the root endodermis form transport barriers to water and solutes (Peterson et al. 1993; Peterson and Cholewa 1998; Steudle and Peterson 1998). In our study, across positions, the suberization in endodermis increased with water-deficit intensity in all rice cultivars (Fig. 7a-c and Fig. S2), which would restrict the apoplastic water flow in water-deficit roots, and eventually lead to the reduction of overall root hydraulic conductance under water deficit (Schreiber et al. 1999; Vandeleur et al. 2009; Kreszies et al. 2018). In wheat, the endodermis appeared heavily suberized at the sections near the root-shoot-junction but weakly suberized at the sections closer to the root apex, and the suberization responded little to water-deficit treatments (Fig. 7a-c and Fig. S2). Such developmental differences along a root were accompanied by differences in hydraulic conductance in a highly and successfully drought-adapted plant, Agave deserti (North and Nobel 2000). It is an advantage for plants to increase suberization in the older basal part of the roots under water deficit to minimize the backflow of water to the drying soil (Steudle and Peterson 1998; Steudle 2000). At the same time, the apical part of the roots continuously grows into deeper wet soil layers acquiring water. Kreszies et al. (2018) observed an increased suberization at different root zones but not in the youngest zone near the root apex in barley plants under water-deficit conditions. This suggests that, at least from the 
histochemical point of view, roots of dryland cereals are better programmed to adapt to water-deficit conditions than rice roots. It is possible that rice roots adapt to drying soil by preventing water from leaking out of the stele (Henry et al. 2012), thereby also impeding the radial water transport into the stele. Wheat roots minimize water loss in the root zone near the root-shoot junction while maintaining water absorption in the apical portions where water availability is higher than the upper soil. All these support our second hypothesis that suberization of root endodermal cell layers and other anatomical features allowed dryland cereals having a better radial water transport ability than rice under water deficit. Our observation that the suberization under water deficit was increased to a lower extent in upland than in lowland and aerobic rice genotypes but still more than in wheat (Fig. 7a-c), suggests that rice adaptation to upland environments for a higher radial transport capability was only a small adjustment.

Consequences of anatomical and histochemical changes on root growth

Perhaps as consequences of different stress responses in water transport capabilities, wheat had higher abilities than rice in maintaining root growth (root biomass, total root length) and fine-to-thick root ratio under waterdeficit treatments, at both stages (Fig. 8). Although some genetic variation within a species was observed, morphological differences were most apparent between species and between treatments.

Although our plants were grown in relatively restricted pots, the observed root morphological changes in rice and wheat are consistent with those previously reported (Reynolds et al. 2006; Henry et al. 2012). Even without any sign of water stress (leaf rolling and drying), rice and wheat plants experienced water shortage - having decreased leaf water potential at both stages (Table S1). More specifically, the root growth of rice plants was impeded by both treatments with varying degrees (Fig. 8). The highest water deficit treatment we imposed to rice in this study (SD condition with soil potential between $-20 \mathrm{kPa}$ to $-40 \mathrm{kPa}$ ) was similar to the aerobic culture used by Kato and Okami (2011). It appears that rice roots respond to aerobic conditions as they were under water-deficit stress (Kato and Okami 2011; Henry et al. 2012). On the other hand, increase in absolute root mass in response to water deficit has been shown previously in wheat (Reynolds et al. 2006). In our study, the root growth of wheat cultivars was not very sensitive to water deficit treatments (Fig. 8).

In our study, the severe reduction of biomass and total root length under water deficit in rice (Fig. 8) was associated with the strong lignification along the root (Fig. 7d-f and Fig. S3). In contrast, root growth and lignification were least affected by water deficit treatments in wheat roots (Figs. 7d-f and 8 and Fig. S3). Lignification is an energy-consuming process. The increase in lignin deposition in roots was accompanied by decreased root growth in several water-deficit-stressed plants (Steudle 2000; Fan et al. 2006; Yang et al. 2006; Kováč et al. 2018). In maize, the inhibition of root growth under water deficit was shown to be associated with the increased expression of genes involved in the biosynthesis of lignin and with the deposition of lignin in the elongating zone of the root (Fan et al. 2006). Similar results were obtained in rice roots, when plant encountered water deficit after 48 to $72 \mathrm{~h}$ (Yang et al. 2006). Moreover, the advanced lignification in rice root under water deficit conditions might be a trade-off mechanism for preventing xylem embolism, as the stem xylem embolism resistance in herbaceous requires upregulation of the lignin pathway (Lens et al. 2016; Dória et al. 2018).

Rice plants promote the emergence of nodal root in inundated environments to alleviate hypoxia stress (Mergemann and Sauter 2000; Steffens and Rasmussen 2016). The severe decline of rice root biomass and total root length under water deficit (Fig. 8a and b) might be associated with the down-regulated nodal root number as previously shown in rice plants grown in dry soil (Suralta and Yamauchi 2008; Kato and Okami 2011; Hazman and Brown 2018). Furthermore, the significantly decreased lateral root length per nodal root length (fine-to-thick root length ratio) under water deficit in rice (Fig. 8c) should also be responsible for the severe reduction of root biomass and total root length, as lateral roots account for a large proportion of the total root system in terms of root length and number (Henry et al. 2012).

Lateral root plasticity is a variable trait in plant adaptation to water-deficit conditions (Niones et al. 2012; Zhan et al. 2015). Water deficit decreased lateral root formation in shallow soil layers and increased lateral root branching density and length in at deeper soil layers when rice plants grown in mesocosms (Hazman and Brown 2018). However, this might differ in field conditions. Unlike dryland cereals, rice plants are generally 
having a shallow rooting system with decreased lateral root branching when grown in aerobic and dry fields (Kato and Okami 2011; Uga et al. 2013). We observed a large reduction of lateral root formation in rice genotypes under water-deficit conditions (Fig. 8c). On the contrary, wheat maintained or even increased lateral root branching under stress treatments (Fig. 8c). This would in turn allow for a better water acquisition from water-limited soil, as lateral roots provide the greatest surface area with the least investments in biomass (Waisel and Eshel 2002; Wasson et al. 2012; Postma et al. 2014; Tylová et al. 2017).

In our study, we only examined the root anatomical and histochemical properties, which might influence the water transport under water-deficit conditions. We observed large differences on the anatomical barrier between rice and wheat root. Although there is lack of physiological measurements on the axial and radial conductivities in our study, the barrier formation in rice root under water deficit is evident. However, although it is not covered by this study, the modification of other cell wall structures such as Casparian bands should not be neglected. The presence and number of Casparian bands would also affect the apoplastic water transport between root cells (Tylová et al. 2017). In addition, the symplastic connections with plasmodesmata across endodermis create intercellular passages for passive movement of nutrients and water (Rutschow et al. 2011), and thus, could be important for water transport under waterlimited condition. Furthermore, the role of certain biochemical components such as aquaporins cannot be excluded. Research on barley roots indicated that osmotic stress impeded the hydraulic conductance of the apoplastic pathway by altering histochemical and anatomical features, but had little influence on aquaporin expression, thus did not alter the hydraulic conductance of the cell-to-cell pathway (Kreszies et al. 2018). Further studies would be needed to obtain insights into possible roles of aquaporins and plasmodesmata for rice adaptation in drier soil conditions. Moreover, it is also necessary to examine how shoot morphology and anatomy respond to water-deficit stress in various rice and wheat genotypes.

\section{Conclusions}

Rice and wheat cultivars showed distinct root morphological, anatomical and histochemical responses at both developmental stages to long-term water-deficit treatments. The larger proportion of aerenchyma, smaller stele and xylem in rice, compared to wheat, would lead to a lower axial conductance. The highly suberized, lignified and thickened endodermal cell walls at the region close to the root apex in rice roots formed strong barriers for radial water transport into the stele. As a result, water-deficit stress limited root growth and lateral root proliferation, resulting in a significant decrease in root biomass and total root length in rice, at both vegetative and flowering stages. Our comprehensive comparison of two species demonstrated the difference of the root structures in adaptation to water-deficit stress. Our results suggest that rice could grow like dryland cereals after a genetic modification of its root anatomical and histochemical traits in a way that increases radial and axial water transport.

Acknowledgements This work was supported by an anonymous private donor who financed, via Wageningen University Fund, the first author's PhD fellowship. The experimental work was financed by the College of Agriculture, Yangzhou University. We thank IRRI and CIMMYT for providing rice and wheat seeds, Mrs Zhiqin Wang and Mr. Zhenxiang Zhou for assistance during experimentation, and Dr. G. van der Linden, Dr. P. S. Bindraban and Dr. K.S.V. Jagadish for valuable support.

Author contributions XY and PCS conceived the project; WO, $\mathrm{XY}$ and JY designed the research; WO performed the experiments and data analysis, and wrote the draft; XY, PCS and JY revised the manuscript.

Open Access This article is licensed under a Creative Commons Attribution 4.0 International License, which permits use, sharing, adaptation, distribution and reproduction in any medium or format, as long as you give appropriate credit to the original author(s) and the source, provide a link to the Creative Commons licence, and indicate if changes were made. The images or other third party material in this article are included in the article's Creative Commons licence, unless indicated otherwise in a credit line to the material. If material is not included in the article's Creative Commons licence and your intended use is not permitted by statutory regulation or exceeds the permitted use, you will need to obtain permission directly from the copyright holder. To view a copy of this licence, visit http://creativecommons.org/licenses/by/4.0/.

\section{References}

Abiko T, Kotula L, Shiono K, Malik AI, Colmer TD, Nakazono M (2012) Enhanced formation of aerenchyma and induction of a barrier to radial oxygen loss in adventitious roots of Zea nicaraguensis contribute to its waterlogging tolerance as 
compared with maize (Zea mays ssp. mays). Plant Cell Environ 35:1618-1630

Abràmoff MD, Magelhães P, Ram S (2004) Image processing with ImageJ. Biophotonics Int 11:36-42

Argus RE, Colmer TD, Grierson PF (2015) Early physiological flood tolerance is followed by slow post-flooding root recovery in the dryland riparian tree Eucalyptus camaldulensis subsp. refulgens. Plant Cell Environ 38:1189-1199

Atlin GN, Lafitte HR, Tao D, Laza M, Amante M, Courtois B (2006) Developing rice cultivars for high-fertility upland systems in the Asian tropics. Field Crops Res 97:43-52

Baluska F, Ciamporová M, Gasparíková O, Barlow PW (2013) Structure and Function of Roots: Proceedings of the Fourth International Symposium on Structure and Function of Roots, June 20-26, 1993, Springer Science \& Business Media, Stará Lesná

Bouman BAM, Peng S, Castaneda AR, Visperas RM (2005) Yield and water use of irrigated tropical aerobic rice, systems. Agric Water Manage 74:87-105

Bramley H, Turner NC, Turner DW, Tyerman SD (2009) Roles of morphology, anatomy, and aquaporins in determining contrasting hydraulic behavior of roots. Plant Physiol 150:348364

Brundrett MC, Enstone DE, Peterson CA (1988) A berberineaniline blue fluorescent staining procedure for suberin, lignin, and callose in plant tissue. Protoplasma 146:133-142

Calkin HW, Gibson AC, Nobel PS (1986) Biophysical model of xylem conductance in tracheids of the fern Pteris vittata. J Exp Bot 37:1054-1064

Centritto M, Lauteri M, Monteverdi MC, Serraj R (2009) Leaf gas exchange, carbon isotope discrimination, and grain yield in contrasting rice genotypes subjected to water deficits during the reproductive stage. J Exp Bot 60:2325-2339

Chimungu JG, Brown KM, Lynch JP (2014) Reduced root cortical cell file number improves drought tolerance in maize. Plant Physiol 166:1943-1955

Cochard H (2002) Xylem embolism and drought-induced stomatal closure in maize. Planta 215:466-471

Colmer TD (2002) Aerenchyma and an inducible barrier to radial oxygen loss facilitate root aeration in upland, paddy and deep-water rice (Oryza sativa L.). Ann Bot 91:301-309

Comas L, Becker S, Cruz VMV, Byrne PF, Dierig DA (2013) Root traits contributing to plant productivity under drought. Front Plant Sci 4:442

Dória LC, Podadera DS, del Arco M, Chauvin T, Smets E, Delzon S, Lens F (2018) Insular woody daisies (Argyranthemum, Asteraceae) are more resistant to drought-induced hydraulic failure than their herbaceous relatives. Funct Ecol 32:14671478

Drew MC, He C-J, Morgan PW (2000) Programmed cell death and aerenchyma formation in roots. Trends Plant Sci 5:123127

Enstone DE, Peterson CA (2005) Suberin lamella development in maize seedling roots grown in aerated and stagnant conditions. Plant Cell Environ 28:444-455

Enstone DE, Peterson CA, Ma F (2002) Root endodermis and exodermis: structure, function, and responses to the environment. J Plant Growth Regul 21:335-351

Fan L, Linker R, Gepstein S, Tanimoto E, Yamamoto R, Neumann PM (2006) Progressive inhibition by water deficit of cell wall extensibility and growth along the elongation zone of maize roots is related to increased lignin metabolism and progressive stelar accumulation of wall phenolics. Plant Physiol 140:603-612

Geldner N (2013) The endodermis. Annu Rev Plant Biol 64:531558

Gerlach ZBD (1984) Botanische Mikrotechnik, 3rd edn. Georg Thieme Verlag, Stuttgart

Hazman M, Brown KM (2018) Progressive drought alters architectural and anatomical traits of rice roots. Rice 11:62

Henry A, Gowda VR, Torres RO, McNally KL, Serraj R (2011) Variation in root system architecture and drought response in rice (Oryza sativa): phenotyping of the OryzaSNP panel in rainfed lowland fields. Field Crops Res 120:205-214

Henry A, Cal AJ, Batoto TC, Torres RO, Serraj R (2012) Root attributes affecting water uptake of rice (Oryza sativa) under drought. J Exp Bot 63:4751-4763

Jensen WA (1962) Botanical histochemistry: principles and practice. (No. QK 861. J46)

Kadam NN, Yin X, Bindraban PS, Struik PC, Jagadish KVS (2015) Does morphological and anatomical plasticity during the vegetative stage make wheat more tolerant of waterdeficit stress than rice? Plant Physiol 167:1389-1401

Kano M, Inukai Y, Kitano H, Yamauchi A (2011) Root plasticity as the key root trait for adaptation to various intensities of drought stress in rice. Plant Soil 342:117-128

Kashiwagi J, Krishnamurthy L, Crouch JH, Serraj R (2006) Variability of root length density and its contributions to seed yield in chickpea (Cicer arietinum L.) under terminal drought stress. Field Crops Res 95:171-181

Kato Y, Okami M (2011) Root morphology, hydraulic conductivity and plant water relations of high-yielding rice grown under aerobic conditions. Ann Bot 108:575-583

Kato Y, Abe J, Kamoshita A, Yamagishi J (2006) Genotypic variation in root growth angle in rice (Oryza sativa L.) and its association with deep root development in upland fields with different water regimes. Plant Soil 287:117-129

Kim HK, Park J, Hwang I (2014) Investigating water transport through the xylem network in vascular plants. J Exp Bot 65: 1895-1904

Končalová H (1990) Anatomical adaptations to waterlogging in roots of wetland graminoids: limitations and drawbacks. Aqu Bot 38:127-134

Kotula L, Ranathunge K, Schreiber L, Steudle E (2009) Functional and chemical comparison of apoplastic barriers to radial oxygen loss in roots of rice (Oryza sativa L.) grown in aerated or deoxygenated solution. J Exp Bot 60:2155-2167

Kováč J, Lux A, Vaculík M (2018) Formation of a suberolignified apical deposit in root tip of radish (Raphanus sativus) as a response to copper stress. Ann Bot 221:180-194

Krauss KW, Allen JA, Cahoon DR (2003) Differential rates of vertical accretion and elevation change among aerial root types in Micronesian mangrove forests. Estuar Coast Shelf Sci 56:251-259

Kreszies T, Shellakkutti N, Osthoff A, Yu P, Baldauf JA, ZeislerDiehl VV, Ranathunge K, Hochholdinger F, Schreiber L (2018) Osmotic stress enhances suberization of apoplastic barriers in barley seminal roots: analysis of chemical, transcriptomic and physiological responses. New Phytol 221:180-194

Lee D-K, Jung H, Jang G, Jeong JS, Kim YS, Ha S-H, Do Choi Y, Kim J-K (2016) Overexpression of the OsERF71 
transcription factor alters rice root structure and drought resistance. Plant Physiol 172:575-588

Lens F, Picon-Cochard C, Delmas CE, Signarbieux C, Buttler A, Cochard H, Jansen S, Chauvin T, Dória LC, Del Arco M, Delzon S (2016) Herbaceous angiosperms are not more vulnerable to drought-induced embolism than angiosperm trees. Plant Physiol 172(2):661-667

Lynch JP, Chimungu JG, Brown KM (2014) Root anatomical phenes associated with water acquisition from drying soil: targets for crop improvement. J Exp Bot 65:6155-6166

Ma F, Peterson CA (2003) Current insights into the development, structure, and chemistry of the endodermis and exodermis of roots. Can J Bot 81:405-421

Ma JF, Goto S, Tamai K, Ichii M (2001) Role of root hairs and lateral roots in silicon uptake by rice. Plant Physiol 127: 1773-1780

Madadgar S, AghaKouchak A, Farahmand A, Davis SJ (2017) Probabilistic estimates of drought impacts on agricultural production. Geophys Res Lett 44:7799-7807

McDonald MP, Galwey NW, Colmer TD (2002) Similarity and diversity in adventitious root anatomy as related to root aeration among a range of wetland and dryland grass species. Plant Cell Environ 25:441-451

Mergemann H, Sauter M (2000) Ethylene induces epidermal cell death at the site of adventitious root emergence in rice. Plant Physiol 124:609-614

Miyamoto N, Steudle E, Hirasawa T, Lafitte R (2001) Hydraulic conductivity of rice roots. J Exp Bot 52:1835-1846

Niones JM, Suralta RR, Inukai Y, Yamauchi A (2012) Field evaluation on functional roles of root plastic responses on dry matter production and grain yield of rice under cycles of transient soil moisture stresses using chromosome segment substitution lines. Plant Soil 359:107-120

North GB, Nobel PS (1995) Hydraulic conductivity of concentric root tissues of Agave deserti Engelm. under wet and drying conditions. New Phytol 130:47-57

North GB, Nobel PS (2000) Heterogeneity in water availability alters cellular development and hydraulic conductivity along roots of a desert succulent. Ann Bot 85:247-255

O'Brien L (1979) Genetic variability of root growth in wheat (Triticum aestivum L.). Australian J Agric Res 30:587-595

O'Toole JC, Bland WL (1987) Genotypic variation in crop plant root systems. Adv Agron 41:91-145

Ouyang W, Struik PC, Yin X, Yang J (2017) Stomatal conductance, mesophyll conductance, and transpiration efficiency in relation to leaf anatomy in rice and wheat genotypes under drought. J Exp Bot 68:5191-5205

Pantuwan G, Fukai S, Cooper M, Rajatasereekul S, O’Toole JC (2002) Yield response of rice (Oryza sativa L.) genotypes to different types of drought under rainfed lowlands - Part 1. Grain yield and yield components. Field Crops Res 73:153168

Peng S, Bouman B, Visperas RM, Castañeda A, Nie L, Park H-K (2006) Comparison between aerobic and flooded rice in the tropics: agronomic performance in an eight-season experiment. Field Crops Res 96:252-259

Peng S, Tang Q, Zou Y (2009) Current status and challenges of rice production in China. Plant Prod Sci 12:3-8

Peterson CA, Cholewa E (1998) Structural modifications of the apoplast and their potential impact on ion uptake. $\mathrm{Z}$ Pflanzenernährung Bodenkunde 161:521-531
Peterson CA, Murrmann M, Steudle E (1993) Location of the major barriers to water and ion movement in young roots of Zea mays L. Planta 190:127-136

Pfeiffer WH (1988) Drought tolerance in bread wheat: analysis of yield improvement over the years in CIMMYT germplasm. In: Wheat Production Constraints in Tropical Environments. Chiang Mai, Thailand

Postma JA, Dathe A, Lynch J (2014) The optimal lateral root branching density for maize depends on nitrogen and phosphorus availability. Plant Physiol 166:590-602

Praba ML, Cairns JE, Babu RC, Lafitte HR (2009) Identification of physiological traits underlying cultivar differences in drought tolerance in rice and wheat. J Agron Crop Sci 195: 30-46

Prince SJ, Murphy M, Mutava RN, Durnell LA, Valliyodan B, Shannon JG, Nguyen HT (2017) Root xylem plasticity to improve water use and yield in water-stressed soybean. J Exp Bot 68:2027-2036

Ranathunge K, Kotula L, Steudle E, Lafitte R (2004) Water permeability and reflection coefficient of the outer part of young rice roots are differently affected by closure of water channels (aquaporins) or blockage of apoplastic pores. J Exp Bot 55:433-447

Ranathunge K, Kim YX, Wassmann F, Kreszies T, Zeisler V, Schreiber L (2017) The composite water and solute transport of barley (Hordeum vulgare) roots: effect of suberized barriers. Ann Bot 119:629-643

Reynolds M, Dreccer F, Trethowan R (2006) Drought-adaptive traits derived from wheat wild relatives and landraces. J Exp Bot 58:177-186

Richards RA, Passioura JB (1981) Seminal root morphology and water use of wheat II. Genetic variation. Crop Sci 21:253255

Rutschow HL, Baskin TI, Kramer EM (2011) Regulation of solute flux through plasmodesmata in the root meristem. Plant Physiol 155:1817-1826

Schreiber L, Hartmann K, Skrabs M, Zeier J (1999) Apoplastic barriers in roots: chemical composition of endodermal and hypodermal cell walls. J Exp Bot 50:1267-1280

Steffens B, Rasmussen A (2016) The physiology of adventitious roots. Plant Physiol 170:603-617

Steudle E (2000) Water uptake by roots: effects of water deficit. J Exp Bot 51:1531-1542

Steudle E, Peterson CA (1998) How does water get through roots? J Exp Bot 49:775-788

Suralta RR, Yamauchi A (2008) Root growth, aerenchyma development, and oxygen transport in rice genotypes subjected to drought and waterlogging. Environ Exp Bot 64:75-82

Tylová E, Pecková E, Blascheová Z, Soukup A (2017) Casparian bands and suberin lamellae in exodermis of lateral roots: an important trait of roots system response to abiotic stress factors. Ann Bot 120:71-85

Tyree MT, Ewers FW (1991) The hydraulic architecture of trees and other woody plants. New Phytol 119:345-360

Uga Y, Sugimoto K, Ogawa S, et al., (2013) Control of root system architecture by DEEPER ROOTING 1 increases rice yield under drought conditions. Nature Genet 45:1097

Vandeleur RK, Mayo G, Shelden MC, Gilliham M, Kaiser BN, Tyerman SD (2009) The role of plasma membrane intrinsic protein aquaporins in water transport through roots: diurnal and drought stress responses reveal different strategies 
between isohydric and anisohydric cultivars of grapevine. Plant Physiol 149:445-460

Venuprasad R, Lafitte HR, Atlin GN (2007) Response to direct selection for grain yield under drought stress in rice. Crop Sci 47:285-293

Venuprasad R, Cruz MS, Amante M, Magbanua R, Kumar A, Atlin GN (2008) Response to two cycles of divergent selection for grain yield under drought stress in four rice breeding populations. Field Crops Res 107:232-244

Villareal RL, del Toro E, Mujeeb-Kazi A, Rajaram S (1995) The 1BL/1RS chromosome translocation effect on yield characteristics in a Triticum aestivum L. cross. Plant Breeding 114: 497-500

Vysotskaya LB, Arkhipova TN, Timergalina LN, Dedov AV, Veselov SY, Kudoyarova GR (2004) Effect of partial root excision on transpiration, root hydraulic conductance and leaf growth in wheat seedlings. Plant Physiol Biochem 42:251255

Waisel Y, Eshel A (2002) Functional diversity of various constituents of a single root system. In: Plant roots: the hidden half. CRC Press, Boca Raton, pp 271-296

Wasson AP, Richards R, Chatrath R, Misra S, Prasad SS, Rebetzke G, Kirkegaard J, Christopher J, Watt M (2012) Traits and selection strategies to improve root systems and water uptake in water-limited wheat crops. J Exp Bot 63: 3485-3498

Yang L, Wang CC, Guo WD, Li XB, Lu M, Yu CL (2006) Differential expression of cell wall related genes in the elongation zone of rice roots under water deficit. Russ J Plant Physiol 53:390-395

Zeier J, Schreiber L (1998) Comparative investigation of primary and tertiary endodermal cell walls isolated from the roots of five monocotyledonous species: chemical composition in relation to fine structure. Planta 206:349-361

Zhan A, Schneider H, Lynch J (2015) Reduced lateral root branching density improves drought tolerance in maize. Plant Physiol 168:1603-1615

Zimmermann HM, Hartmann K, Schreiber L, Steudle E (2000) Chemical composition of apoplastic transport barriers in relation to radial hydraulic conductivity of corn roots (Zea mays L.). Planta 210:302-311

Zingaretti SM, Inácio MC, de Matos Pereira L, Paz TA, de Castro França S (2013) Water stress and agriculture. Responses of Organisms to Water Stress, InTech, London

Publisher's Note Springer Nature remains neutral with regard to jurisdictional claims in published maps and institutional affiliations. 